device. The goal is to alleviate perinodal tissue edema and inflammatory response from the device's compression and stretching effect on the AV node. Such therapy has been applied with variable degrees of success after ASO for atrial or ventricular septal defects. ${ }^{5}$

Our case indicates that persistence of second- or thirddegree heart block for more than 72 hours predicts poor outcome. Time is of the essence in this decision-making to avoid ischemia and fibrosis resulting in permanent injury of the AV node. Leaving the device in place and inserting a permanent pacemaker has also been suggested as an option for progressive heart block. ${ }^{4}$ This would certainly avoid the complications of surgery. However, given the safety and efficacy of surgical closure of ASD and the morbidity associated with pacemaker placement, such as equipment malfunction, certain sports restrictions, infection, and requirement of life-long battery changes, prompt surgical explantation of the ASO and ASD closure is warranted early after this complication occurs and if medical therapy fails to provide complete resolution after the first 72 hours.

\section{References}

1. Chessa M, Carminati M, Butera G, Bini RM, Drago M, Rosti L, et al. Early and late complications associated with transcatheter occlusion of secundum atrial septal defect. J Am Coll Cardiol. 2002;39:1061-5.

2. Suda K, Raboisson MJ, Piette E, Dahdah NS, Miro J. Reversible atrioventricular block associated with closure of atrial septal defects using the Amplatzer device. J Am Coll Cardiol. 2004;43:1677-82.

3. Delaney JW, Li JS, Rhodes JF. Major complications associated with transcatheter atrial septal occluder implantation: a review of the medical literature and the manufacturer and user facility device experience (MAUDE) database. Congenit Heart Dis. 2007;2:256-64

4. Nehgme RA, Huddleston AR, Cheatham JP. Progression to late complete atrioventricular block following Amplatzer device closure of atrial septal defect in a child. Pediatr Cardiol. 2009;30:367-70.

5. Yip WC, Zimmerman F, Hijazi ZM. Heart block and empirical therapy after transcatheter closure of perimembranous ventricular septal defect. Catheter Cardiovasc Interv. 2005;66:436-41.

\title{
Eagle-shaped patch to restore mitral-aortic continuity
}

\author{
Samer Kassem, MD, ${ }^{a}$ Francesco Alamanni, MD, ${ }^{\mathrm{a}}$ and Ghassan A. Moasis, MD, ${ }^{\mathrm{b}}$ Milan, Italy, and \\ Damascus, Syria
}

The reconstruction of aortic-mitral continuity is an uncommon procedure occurring in around $1 \%$ of patients undergoing aortic valve replacement, and it is needed more frequently in case of native or prosthetic valve endocarditis (PVE). ${ }^{1,2} \mathrm{In}$ case of PVE, especially with paravalvular abscess, the infected tissue must be removed thoroughly, even if large defects are created, because leaving infected tissue in situ always carries a high risk of recurrent endocarditis.,

We describe a simple technique for the reconstruction of the mitral-aortic continuity with an eagle-shaped patch that avoids tension on the mitral valve or on healthy nearby tissues.

\section{SURGICAL TECHNIQUE}

Before cardiopulmonary bypass is established, transesophageal echocardiography (TEE) is performed to define the

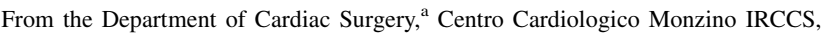
University of Milan, Milan, Italy; and the Department of Cardiac Surgery, ${ }^{\mathrm{b}}$ Assad University Hospital, University of Damascus, Damascus, Syria.

Disclosures: Authors have nothing to disclose with regard to commercial support. Received for publication Aug 10, 2010; accepted for publication Aug 23, 2010; available ahead of print Oct 8, 2010.

Address for reprints: Samer Kassem, MD, Centro Cardiologico Monzino IRCCS, Via

Parea, 4, 20138, Milano, Italy (E-mail: samer.kassem@ccfm.it).

J Thorac Cardiovasc Surg 2011;141:1321-3

$0022-5223 / \$ 36.00$

Copyright (c) 2011 by The American Association for Thoracic Surgery

doi:10.1016/j.jtcvs.2010.08.041
}

anatomic details of the aortic root. Aortic-atrial cannulation for extracorporeal circulation, antegrade and retrograde cold blood cardioplegia, carbon dioxide insufflation of the operative field, and moderate hypothermia $\left(32^{\circ} \mathrm{C}\right)$ are routinely used. The aortic valve is approached through a longitudinal aortotomy, which can be extended into the noncoronary sinus, into the intervalvular fibrous body, and into the anterior mitral leaflet. Once the aortic-mitral continuity needs to be reconstructed, because of the need to remove infected tissue or because of aortic root enlargement, a bovine pericardial patch is used. This patch $(60 \times 30 \mathrm{~mm})$ is prepared by folding it into 3 equal folds at its central part, the height of the folds being about $0.5 \mathrm{~cm}$; the 3 folds are fixed by 2 or 3 interrupted simple sutures of 4-0 polypropylene. At the end, the patch looks like an eagle with 2 wings and a central body (Figure 1, $A$ ).

The 2 sides of the body of the eagle patch are sutured to the lateral and medial fibrous trigones with 2 single stitches of 3-0 polypropylene. Then, the lower wing of the patch is secured without tension to the anterior mitral leaflet with a 5-0 polypropylene locked running suture, whereas the upper wing is sutured to the healthy aortic wall using 4-0 polypropylene running suture (Figure 1, B). Once the body and the wings of the patch are sutured, the body of the eagle patch completes and re-establishes the aortic annulus, which now will be able to accommodate a prosthesis without tension (Figure 2). This is important both on the lower 

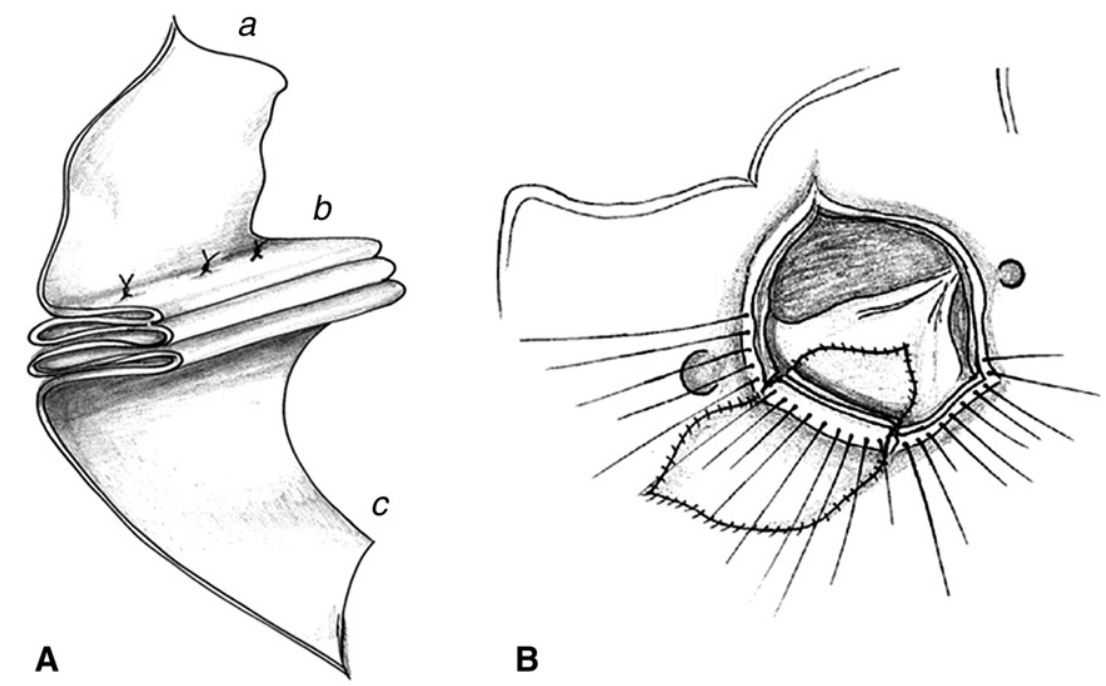

B

FIGURE 1. A, The assembly of the eagle-shaped patch: after the multiple folding in its central part, the upper wing $(a)$, the central body $(b)$, and the lower wing $(c)$ can be easily recognized. B, Suturing of the eagle-shaped patch to the aortic wall (upper wing, 4-0 polypropylene running suture) to the anterior mitral leaflet (lower wing, 5-0 polypropylene locked running suture). Finally, the body of the eagle-shaped patch completes the board of the aortic annulus and is connected at its ends with a single 3-0 polypropylene stitch.

wing (where any tension on the anterior mitral valve could cause mitral valve insufficiency) and on upper wing (to avoid bleeding from sutures).

\section{RESULTS}

We have used this technique on 2 patients, a 56-year-old man with a late PVE (case 1) and a 70-year-old woman with an early PVE (case 2) after aortic valve replacement.

In both cases, intraoperative TEE showed paravalvular leakage and destruction of the aortic annulus, with a cavity in the fibrous curtain between the medial and lateral fibrous trigones extending into the base of the anterior leaflet; also, a perforation of the base of anterior leaflet of the mitral valve into the left atrium was demonstrated in case 1 .

After the removal of all infected and necrotic tissue around the annulus and within the abscess, the eagleshaped patch was inserted and secured as previously described, followed by aortic valve replacement with a mechanical (case 1) or biologic (case 2) aortic valve prosthesis.

The postoperative TEE showed a well-seated prosthetic aortic valve without any anomalous shunt and with correct function of the anterior leaflet of the mitral valve (images available from the authors on request). Both patients are alive and free from infection or need of reintervention 45 and 6 months after surgery, respectively.

\section{COMMENT}

The reconstruction of aortic-mitral continuity during aortic valve replacement may be the only option to treat some patients with active, destructive endocarditis, with small aortic annuli, or with inadequate annular tissue owing

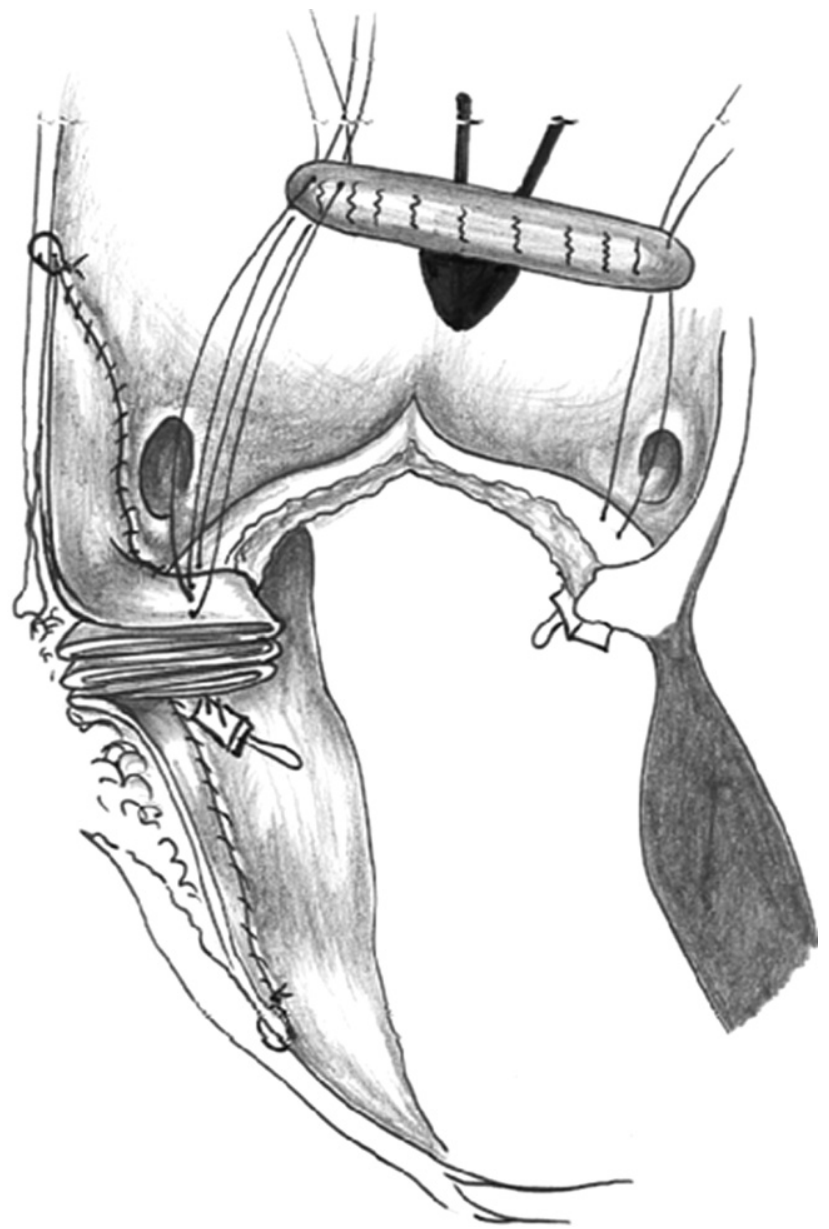

FIGURE 2. Seating of the prosthesis on the body of the eagle-shaped patch. 
to multiple previous operations. ${ }^{1,2}$ In all these cases, and especially in case of PVE, the destruction of the architecture of the aortic root or the deficient aortic root tissues is a serious problem complicating aortic valve replacement, leading mortality rates as high as $20 \%$ to $30 \%{ }^{4,5}$

The eagle-shaped patch technique that we used in 2 cases of PVE, but that we believe could be considered even in the case of a small aortic root, is an easy and quick way to prevent the problems that may occur in the aortic-mitral areamalfunctioning of the mitral valve owing to overstretching of the anterior mitral leaflet and suture dehiscence owing to excessive tension on the reconstructed areas. Finally, with the "eagle" body, a complete reconstruction of the annulus and an easy and correct seating of the aortic prosthesis can be done.
Longer follow-up is obviously necessary to prove the effectiveness of our technique.

\section{References}

1. David TE, Kuo J, Armstrong S. Aortic and mitral valve replacement with reconstruction of the intervalvular fibrous body. J Thorac Cardiovasc Surg. 1997;114: 766-71; discussion 71-2.

2. David TE, Bos J, Christakis GT, Brofman PR, Wong D, Feindel CM. Heart valve operations in patients with active infective endocarditis. Ann Thorac Surg. 1990; 49:701-5

3. Mills SA. Surgical progress: surgical management of infective endocarditis. Ann Thorac Surg. 1982;195:367-83.

4. Vogt PR, von Segesser LK, Jenni R, Niederhauser U, Genoni M, Kunzli A, et al Emergency surgery for acute infective aortic valve endocarditis. Performance of cryopreserved homografts and mode of failure. Eur J Cardiothorac Surg. 1997; 11:53-61.

5. Edwards MB, Ratnatunga CP, Dore CJ, Taylor KM. Thirty-day mortality and longterm survival following surgery for prosthetic endocarditis: a study from the U.K. Heart Valve Registry. Eur J Cardiothorac Surg. 1998;14:156-64.

\section{Totally thoracoscopic resection of a superior mediastinal tumor extending above the thoracic inlet}

Toshiki Tanaka, MD, PhD, Kazuhiro Ueda, MD, PhD, Masataro Hayashi, MD, PhD, and Kimikazu Hamano, MD, PhD, Yamaguchi, Japan

The resection of superior mediastinal tumors extending above the thoracic inlet (extended superior mediastinal tumor) usually requires both transthoracic and transcervical approaches, either via thoracotomy in combination with a supraclavicular incision or via sternotomy, which imposes considerable stress on the patient. To reduce the excessive invasiveness, some surgeons have attempted to remove these tumors via video-assisted thoracic surgery, but this has always required simultaneous partial sternotomy or a supraclavicular incision. ${ }^{1,2}$ We report our initial experience of performing totally thoracoscopic resection of extended superior mediastinal tumors, without the need for transcervical access, in 2 patients. We believe that both technical and instrumental refinement contributed to the successful outcome of this challenging operation.

\footnotetext{
From the Department of Surgery and Clinical Science, Division of Chest Surgery, Yamaguchi University Graduate School of Medicine, Ube, Yamaguchi, Japan.

Disclosures: Authors have nothing to disclose with regard to commercial support.

Received for publication June 11, 2010; revisions received Aug 5, 2010; accepted for publication Aug 25, 2010; available ahead of print Nov 12, 2010.

Address for reprints: Toshiki Tanaka, MD, PhD, 1-1-1 Minami-kogushi, Ube, Yama-

guchi 755-8505, Japan (E-mail: toshik@yamaguchi-u.ac.jp).

J Thorac Cardiovasc Surg 2011;141:1323-5

$0022-5223 / \$ 36.00$

Copyright (c) 2011 by The American Association for Thoracic Surgery

doi:10.1016/j.jtcvs.2010.08.078
}

\section{CLINICAL SUMMARY}

Surgery is performed totally thoracoscopically via a 3-access port, eliminating the need for direct vision. The primary surgeon always stands to the right of the patient, and the assistant always stands to the left of the patient. The primary surgeon inserts the endoscopic instruments via the proximal 2 access ports on his/her side, and the assistant inserts the thoracoscope via the port on his/her side (Figure 1, $A$ ). The assistant simultaneously inserts the endoscopic dissector via the same port to create the best operating view.

\section{Patient 1}

A 67-year-old man was referred to Yamaguchi University hospital for surgical treatment of a superior mediastinal tumor. A chest computed tomography (CT) scan showed that the tumor comprised cystic and solid parts and was located in the right side of the superior mediastinum, extending to the cervical area just below the thyroid (Figure 2, A). Magnetic resonance imaging showed similar findings. These findings mimicked a mediastinal thyroid tumor. We attempted a total thoracoscopic resection of the tumor. Meticulous manipulation was necessary to dissect the feeding vessels from the inferior thyroidal artery and vein, and preserve the vagal nerve and recurrent nerve adjacent to the tumor in the thoracic inlet. The feeding vessels were divided, and the tumor was 